\title{
The Kimberley Meeting of the South African Association for the Advancement of Science.
}

$\mathrm{T}^{\mathrm{H}}$

HE twenty-sixth annual meeting of the South African Association for the Advancement of 1928, under the presidency of Sir J. Carruthers Beattie. The meeting was well attended, and eighty-six papers were read. Joint meetings of several sections were held. The South Africa medal and grant were presented to Dr. H. H. Green at the conclusion of the presidential address. A popular, illustrated lecture was given by Prof. P. Kirby on "Primitive and Exotic Music." There was a reception by the Mayor and city councillors in the City Hall, and visits to various places of scientific interest in Kimberley and the neighbourhood.

The president, Sir Carruthers Beattie, took as the subject of his address "Some Possible Extensions of the Activities of the Association." He gave an account of the first magnetic survey of South Africa, and emphasised the necessity of repeating a magnetic survey at not too long intervals. A re-survey has recently been begun in South Africa and its importance was indicated, particularly in regard to aviation and to the location of minerals and oil. The study of the problems of African peoples was indicated as a field for further work. Much research had been done in practically every field, but more was needed. The effect of present and prospective African industrialism on European and other industries might be investigated. As a body the Association might undertake the co-ordination and dissemination of the knowledge already available. The question of the extent to which the Bantu was capable of development affected not only South Africa, but also the world. The presence and determination of the European to remain in certain parts of Africa created the native question from the European point of view and the European question from the native point of view. The possibility of persistence of the white in South Africa, as occurred in other continents, needed investigation. Whites and natives both so far flourished, but how these non-homogeneous elements were to continue needed research. The possibilities were racial amalgamation resulting in a new race, or domination of one race by another, or development of the races on their own lines. The domination policy was considered as never succeeding permanently. The Bantu were assimilating European ideals and culture rapidly. Guidance in the science of government would be necessary. The possibility of development of the Bantu to a degree comparable with our own, and the assumption that the white knew best what was good for natives, needed consideration. The problems of population and food supply in parts of South Africa, of the second Oriental generation in Africa, and the effect of the native in European industry, also were indicated for research. "By research, discussion, and publication we can make a contribution of value towards the solution of Africa's greatest problem."

The presidential address to Section A was given by Dr. J. S. van der Lingen, his subject being "Garnets." Garnets as associates of diamonds were noted. The classification as aluminous and non-aluminous garnets was shown as applying to 'ideal ' garnets, those found being isomorphous mixtures. The spectroscopic examination of garnets was described in detail. From numerous examinations it was concluded that yttriferous garnets are not rare in South Africa. The name proposed for this type of garnet, namely, a spessartine containing yttrium, is emildine, the limitation being that molecules of uvarovite must be absent and the molecule of pyrope either absent or a trace. In another type of garnet from other localities the molecule of pyrope was conspicuous. Magnesium and chromium were the determining elements in garnets derived from kimberlite. Yet another type of garnet, designated erinadine, contained both pyrope and uvarovite; but unlike the pipe garnets, they also contained yttrium. The absorption spectra of garnets were discussed and the application of these methods of examination of garnets to the detection of the presence of kimberlite pipes was indicated.

"The Liquid Fuel Problem" was the subject of Prof. J. Smeath Thomas's address to Section B. Adequate and continuous supply of liquid fuel was essential for national welfare. The general tendency to use oil instead of coal was shown by ship construction and mechanised transport. The possible exhaustion of the world's oil deposits was discussed, and it was concluded that there was no immediate danger. In non-oil producing countries fears in this direction were really due to political and strategic considerations. The oil position in the United States is such that control of the world's petrol reserves must pass from it, just as control of the coal market has passed from Great Britain. Petroleum substitutes and admixtures were considered. Alcohol mixed with petrol and benzene provided an excellent motor spirit. The production of fuel alcohol from home-grown materials was of special importance in South Africa, where large quantities of waste vegetable products and rank grasses were available. Sawdust and wood waste, ethylene and acetylene also were considered. The production of liquid fuel from oil shale and other carbonaceous rocks by destructive distillation was considered, and the value of by-products such as ammonium sulphate, in addition to the oil, was considerable. Coal as the source of future supplies of liquid fuel was of the greatest importance, and South Africa had abundance of suitable coal. The various methods of producing liquid fuel from coal-by low temperature carbonisation, the Bergius process, conversion into water gas, and synthesis of alcohols and hydrocarbons from this by catalysts--were discussed. The establishment of a Fuel Research Institute was urged.

In his presidential address to Section C, Mr. J. S. Henkel dealt with "The Relation of Vegetation to Water Supply in Southern Rhodesia." In Rhodesia summer rainfall prevails. Grassland and woodland are the principal types of vegetation, the latter being either close types (high forest) or savannah. About 60 per cent of the Colony is woodland. Most of the savannah trees are deciduous. Where human influence is not conspicuous, crowded trees of large dimensions and tall growth occur in high forest, small trees in savannah. Native shifting cultivation has caused much deforestation, but scrub is largely scanty regrowth of savannah. The heaviest rainfalls are along the eastern boundary, and rainfall distribution and vegetation maps do not coincide. Five groups of grasslands are differentiated. Extensive level areas occur on the main plateau, which become waterlogged in summer. Grass is the climax type. When drainage occurs, trees take possession. The second group occurs on ridges or narrow plateaux where excessive water supply in the growing season excludes trees. The third group has soil sufficient for grass but not for trees. The fourth is where neither excessive water supply nor shallow soil is present. The fifth group is along the eastern border mountains, the grassland being of an ancient type. Indigenous forest encroaches on grassland if not disturbed by man. Close

No. 3083, VoL. 122] 
type or high forest is confined to areas of abundant rainfall and high elevation. They are not extensive and are mostly evergreen. Streambank forests of evergreens occur at all elevations where there is permanent water. Lists of the trees in the various sites were given. The western high veld showed Baikioea plurijuga and Copaifera coleospermia were dominants, but in parts invasion by Brachystegia and Berlinia was occurring. Ridges at heads of valleys with eastern and southern aspects had Uapaca as the dominant. It formed abundant humus, hence deforestation by natives occurred. The mountain Acacia group was described and the BrachystegiaBerlinia savannah association. In the low veld, Copaifera mopane is the dominant tree. The type species of savannah forest change with elevation and therefore with water supply. The study of vegetation and its trend may indicate whether the climate is becoming wetter or drier, an important problem to South Africa.

The president of Section D, Prof. P. J. du Toit, spoke of "The Significance of Zoology in Veterinary Science" in his address. The early history of veterinary science dated to 4000 years ago, but modern science began in the eighteenth century. Outstanding discoveries of the late nineteenth century were those of the trypanosome causing surra, and of the Babesia responsible for redwater in cattle. These illustrated how veterinarians seeking the cause of disease had to focus their attention on the microscopic and invertebrate world. The study slowly emerged from empiricism and gradually began to embrace biology as a whole. The Protozoa as disease excitants had led to intensive study of the group, accompanied at first by the creation of numerous species, now reclassified under relatively few names, the rest being synonyms. The characters of these standard forms and their synonyms were given. The Piroplasms were similarly considered. Among the Metazoa, the veterinarian and zoologist have common ground in the study of the Cestoda of domestic stock and in the search for intermediate hosts of other parasitic worms. For the determination of such life histories a good knowledge of zoology is essential. A necessary part of the equipment of every veterinarian is a knowledge of the systematics, anatomy, and biology of insects, mites, and ticks. In no group was the common interest of veterinarian and zoologist more clear than in the vertebrates. Anatomy, physiology, and embryology all demanded the comparative method of study for the best results. Many species of mammals were carriers of organisms pathogenic to domestic animals. The diseases of birds are assuming greater importance yearly, as are those of fish. In veterinary education in South Africa an attempt has been made to break away from the more stereotyped course of the older schools and to give to the students the broad scientific bases necessary. Special courses in protozoology, entomology, and helminthology have been instituted. It is hoped that adequate recognition of the value of zoology will enable the younger generation of veterinarians to maintain a leading position for South Africa in veterinary science.

"The Study of Social Structure" was the subject of the address by Prof. T. T. Barnard to Section E. South Africa was a great field for the study of cultural anthropology, and there was urgent need for sympathetic knowledge of the social forms of the Southern Bantu. The study of man's socialised behaviour overlapped with other branches of anthropology. The main divisions of anthropology are ethnography, ethnology, and social anthropology. The methodology of ethnography was discussed, and need for both field work and theoretical treatment by the same investi- gator emphasised. Both ethnology and social anthropology take their subject matter from ethnographical records. The ethnology of the Southern Bantu was the historical analysis of their distribution, development, history, evidence for possible external influences, and transmission of cultural traits from group to group, of which illustrations were given. In social anthropology there was the search for general principles underlying the varieties of cultural form. Historical reconstruction of the prehistoric past is the legitimate aim of ethnology, but the principles of cultural development could only be demonstrated by inductive study of social change. The method of studying cultural variation and development must be inductive. Social anthropology is mainly concerned with the standards of social behaviour, and their analysis is one that will explain the forms as expressions of the needs of the society in which they occur. The study of social groupings is fundamental for the discussion of adjuncts of group differentiation. The three main problems are the actual distinctions existing between individual members of society, the operation of some criterion of similarity for the formation of social groups and the expression of group membership in the behaviour of its constituent members by the observance of group obligations. As examples, problems of kindred differentiation were considered and, i.s particular, the four methods of incest extension amozy the Bantu-speaking peoples of Southern Africa.

The presidential address to Section $\mathrm{F}$ was delivered by Dr. M. Boehmke, who dealt with "Some Social Implications of the Poor White Problem." It was pointed out that in South Africa there was a group of persons known as ' poor whites,' who were becoming an ever-increasing burden to the population. The poor white problem was considered to be due to remediable economic and social causes, such as the mental attitude towards manual labour, the presence of a coloured race at a lower level of civilisation, inheritance laws, exploitation by landowners, geographical and social isolation, laziness, misfortunes such as droughts, and, above all, ignorance. The solving of the problem of the poor white was essential. Early marriage and intermarriage had produced much feeble-mindedness. The non-intelligent ballot must be considered. The social whole must assume responsibility. The mental survey was of much use, but the social survey, organised along proper lines, was considered to be the best mode of attack. Such a survey must be local, definite, and public. Every house, family, and organisation must be included. Co-ordination and intensification of all uplifting efforts would eliminate the poor white problem in a generation, it is believed. The positive force for good would be appreciable when the poor white was brought to a normal position in life and he should become an asset to the country.

A few remarks may be made on the subjects dis. cussed in the various sections :

In Section A, mathematical and engineering problems were to the fore, the maximum and minimum values of a function determined by the method of undetermined multipliers, the elastic impact of a sphere on a plane fixed surface and graphical solutions of electrical engineering problems being discussed.

In Section B an apparatus for observing changes in electrical conductivity in immersed paint films was described, a useful account of the medicinal springs of South Africa was given, the geological problems connected with the occurrence of kimberlite, and with the formation of red soil and of black vlei soil from dolerite in Rhodesia were discussed.

In Section $\mathrm{C}$ several papers of veterinary interest were taken at a joint meeting with Section D. These dealt with the poisonous plants, Bowiea volubilis and

No. 3083, VoL. 122] 
Cucumis myriocarpus, rapid agglutination tests in calf paratyphoid, and Salmonella infections in canaries. Mycological papers were given on various new South African fungi, South African Salicornia and some natural hybrids were described, valuable practical notes on the reclamation of drift sands were given, very interesting accounts of plant indicators and of the forest types in the Knysna region were presented, and pharmocologists found much interest in an account of South African medicinal and poisonous plants.

A wide range of subjects was discussed in Section D. Many topics of interest to veterinarians and pathologists, as well as to zoologists, were considered, among these being the experimental induction of infection with Trypanosoma vivax in sheep and goats, gross invasion of the liver of lambs by cysticerci, fat necrosis, fatty infiltration of the liver, and bent-leg in sheep. East Coast fever and immunity therein was also considered, and some interesting facts regarding longevity of the brown tick without feeding were given, the latter having some significance in explaining sporadic outbreaks of disease. The adhesion reaction in trypanosomiasis and new methods in diphtheria prevention were also considered, and the culture of Crithidia melophagia from the blood of South African sheep described. The Protozoa found in South African soils, wherein a series of comparisons of the protozoal fauna of soils from the Knysna Forests was made, and an account of some new plant-inhabiting Herpetomonads were of much interest. A case of human infestation by Armillifer armillatus, showing southernward extension of the range of the Porocephalid parasite, was described. A series of papers dealt with crimps and quality estimations of grease wool, the standardisation of quality numbers and fibre variation in the merino. Some valuable observations on the formation of nonnucleated blastospheres in the eggs of a spider were detailed. The natural history of the "Loerie' (Turacus) in the Knysna Forests and its rôle in seed dispersal were described. Some physiological papers dealt with the chromatic function in Xenopus, excitement pallor in chameleons, the relation of electrolytes to cardiac rhythm in Octopus and Palinurus, the hydrogen-ion concentration of the waters around the Cape Peninsula. A study of the zoogeographical relationships of certain insect groups was of much interest.

In Section E, stone implements and their significance were to the fore, the stone culture of Victoria West, implements from Howieson's Poort and stone bracelets being described. The Middle Stone Age in South Africa was defined and an account given of the implements in Sir Langham Dale's collection. Strandlooper excavations at Knysna were also described. The political organisation of the Bechwana, the religion of the Bapedi, and the magic medicine of the Hottentots also evoked interest.

In Section F, philosophy and economics were the chief topics. The philosophers discussed some aspects of the approach of philosophy and science, the social significance of art, the psychology of advertising, the nature of perception, and there was a joint meeting with Section D for a paper on industrial psychology. Other papers dealt with the Stanford revision vocabulary test, the first results of the Porteus maze test to native school children. Much interest was aroused by notes on some native budgets collected in Durban.

The next annual meeting of the Association, under the presidency of the Hon. J. H. Hofmeyr, will be held in July 1929, when the South African Associa. tion for the Advancement of Science will merge with the British Association, members of which will meet in South Africa as guests of the South African Association.

\section{The Evolution of Human Races.}

THE Huxley Memorial Lecture of the Royal Anthropological Institute was delivered by Sir Arthur Keith in the lecture hall of the Royal Society on Tuesday, Nov. 27, at 8.30 p.m., when Prof. J. L. Myres, president of the Institute, took the chair. Sir Arthur Keith took for his subject "The Evolution of Human Races." He traced Huxley's career as an anthropologist, and said that in his opinion, his final conclusion that the chief types or races of existing mankind can be reduced to four, is still the most acceptable working hypothesis. Huxley's four chief types are represented by the fair people of Europe (his Xanthochroi), the negro of Africa, the Mongol of Asia, and the aborigine of Australia. The less differentiated types or races Huxley regarded as intermediate in characterisation to his main types, and was disposed to look upon them as having arisen by various degrees of miscegenation of the main types.

That peoples have arisen by the mixing of diverse races cannot be denied, but the chief problem which has to be solved is the origin of the chief types, which cannot be explained by any theory of hybridisation. The only valid explanation is Darwin's, which requires restatement in the light of modern knowledge. The theory of the evolution of races as thus restated includes the co-operation of a triple mechanism : (1) physiological processes which regulate the growth of the human body and determine its racial characterisation; (2) an isolating or segregating mechanism, which tends to preserve a local people in its purity, and thus permits physiological processes to work undisturbed through many generations; this isolating mechanism is found to be mainly physiological, but physical barriers also isolate; (3) a selective mechanism represented by changing environment and also by inter-racial competition. If these evolutionary means are sufficient to produce the four chief racial types, they could also have given rise to all secondary and intermediate races. The conclusion was reached that hybridity has played only a subsidiary role in the evolution of differentiated races.

If evolution is true, we ought to find human races in every stage of differentiation. This is what anthropological investigation is now revealing. There are not only Huxley's main or completely differentiated racial types, but there are also nationalities and peoples which represent every stage in the process of differentiation from a zero-point upwards. To races in which every individual is differentiated and can be recognised at sight by physical appearances, Sir Arthur applies the term pandiacritic. If 80 per cent and upwards of the individuals are recognisable, he proposes the name macrodiacritic; if more than 30 but less than 80 per cent, he suggests the name mesodiacritic ; if less than 30 per cent, he names them microdiacritic races.

In conclusion, Sir Arthur applied this more plastic conception of race to the national and racial problems of Europe, in particular to those of the British Isles. Huxley rightly regarded the English, Welsh, Scottish, and Irish nationalities as mixtures of the same two racial stocks - the Nordic and Mediterranean of Europe-and they, from a zoologist's point of view, he held have no elaim to racial status. In a lecture given in 1870 he stated: "If what I have to say in a matter of science weighs with any man who has political power, I ask him to believe that the arguments about the difference between 